\title{
PELATIHAN DAN PENDAMPINGAN PENGEMBANGAN MEDIA PEMBELAJARAN MENGGUNAKAN MICROSOFT POWER POINT DAN CAMTASIA DI SMAMUHAMMADIYAH 11 KOTA PADANGSIDIMPUAN
}

\author{
Andes Fuady Dharma Harahap ${ }^{1)}$; Sahlan Tuah ${ }^{2)}$; Rizky Ariaji ${ }^{3)}$;Viva Mulyana ${ }^{4)}$ \\ ${ }^{1)}$ Pendidikan Ekonomi, FKIP Universitas Muhammadiyah Tapanuli Selatan \\ ${ }^{2)}$ Pendidikan Biologi, FKIP Universitas Muhammadiyah Tapanuli Selatan \\ ${ }^{3,4)}$ Pendidikan Kimia, FKIP Universitas Muhammadiyah Tapanuli Selatan \\ rizki.ariazi@um-tapsel.ac.id
}

\begin{abstract}
Based on the analysis of the situation and the problems faced by the partners, the devotional team will provide a solution to overcome teacher difficulties in developing learning media. The solution will be in the form of training and mentor for teachers in developing learning media with software incombination with Microsoft PowerPoint and Camtasia. The results achieved in this IbM activity are (1) Positive feedback obtained from the school, teachers at SMA Muhammadiyah 11 Padangsidimpuan during the activity. (2) Increasing information on instructional media that can help learning materials for teachers. (3) Teachers can design instructional media that can be adapted to the circumstances surrounding environment. (4) The high motivation and demand for the development of lesson materials through the media more exciting learning.
\end{abstract}

Keywords: Software On Combination Microsoft PowerPoint and Camtasia, Development of Learning Media.

\begin{abstract}
Abstrak
Berdasarkan hasil analisis situasi dan permasalahan yang dihadapi oleh mitra, tim pengabdi akan memberikan suatu solusi untuk mengatasi kesulitan guru dalam mengembangkan media pembelajaran. Solusi yang akan dilakukan berupa pelatihan dan pendampingan bagi para guru dalam mengembangkan media pembelajaran dengan software pada kombinasi Microsoft Power Point dan Camtasia.Hasil yang dicapai dalam kegiatan IbM ini adalah: (1) Diperoleh feedback yang positif dari pihak sekolah, guru-guru di SMA Muhammadiyah 11 Padangsidimpuan selama kegiatan berlangsung. (2) Bertambahnya informasi terhadap media pembelajaran yang dapat membantu bahan pembelajaran bagi para guru. (3) Guru-guru mampu merancang media pembelajaran yang dapat disesuaikan dengan keadaan lingkungan sekitar. (4) Tingginya motivasi dan permintaan untuk pengembangan bahan pelajaran melalui media pembelajaran yang lebih menarik.
\end{abstract}

Kata Kunci: Software Pada Kombinasi Microsoft Power Point dan Camtasia, Pengembangan Media Pembelajaran. 
Andes Fuady Dharma Harahap, dkk.Pelatihan Dan Pendampingan...

\section{PENDAHULUAN}

\section{Analisis Situasi}

Software presentasi merupakan software yang berfungsi untuk membantu membuat file presentasi yang dinamis dengan menggunakan sisipan animasi. Salah satu program yang digunakan untuk membantu presentasi adalah Microsoft Office Power Point. Program ini dikemas menjadi satu dalam produk Microsoft Office yang terdiri dari Word, Excel, Access dan sebagainya. Power Point merupakan aplikasi yang berjalan pada sistem operasi berbasis Windows dan Macintosh. Ada juga aplikasi yang sejenis yang berjalan di sistem Linux yaitu Openoffice Impress, belakangan telah muncul versi untuk Windows juga. Aplikasi presentasi banyak digunakan oleh kalangan perkantoran seperti pebisnis, para pendidik, peneliti, siswa hingga trainer (Team Lab Infokom, 2013).

Richard E. Mayer dalam hasil penelitiannya mengenai pengaruh multimedia komputer terhadap retensi siswa menegaskan beberapa prinsipprinsip yang perlu dipertimbangkan dalam pembuatan desain media pembelajaran interaktif, yaitu: (1) Prinsip Multimedia (keragaman media), (2) Prinsip Keterdekatan Ruang (Hubungan teks dan gambar), (3) Prinsip Keterdekatan Waktu (Menyederhanakan tampilan materi, (4) Prinsip Koherensi (menyingkirkan media tambahan yang tidak terkait dengan materi), (5) Prinsip Modalitas (tata letak teks dan gambar lebih mudah dipahami), (6) Prinsip Redundansi (penguatan), (7) Prinsip Perbedaan Individual (Materi disesuaikan dengan kebutuhan peserta didik yang berpengetahuan rendah (Utomo, 2009).

Camtasia adalah software (perangkat lunak) yang dikembangkan oleh Tech Smith Coorporation. Camtasia ini sendiri digunakan untuk merekam semua aktifitas yang ada pada desktop komputer. Software ini bisa kita manfatkan untuk membuat media pembelajaran berbasis multimedia dan elearning. Camtasia dapat merekam screen yang ada pada desktop, ini berfungsi apabila kita akan membuat suatu video tutorial yang bahan-bahan utamanya terdapat pada desktop komputer. Kita bisa merekam kegiatan browshing kita di internet untuk kemudian kita jadikan video tutorial. Kita juga bisa merekam program atau aplikasi lain yang ada dikomputer kita (Setiawan, 2011).

Perkembangan teknologi informasi ini sangat pesat sehingga mempengaruhi semua aspek termasuk dibidang pendidikan. Kegiatan pembelajaran bersifat konvensional akan berdampak pada kebosanan siswa dan pemahaman konsep dasar yang rendah. Pengetahuan teknologi yang masih rendah membuat guru dan sekolah kewalahan dalam menciptakan kreatif dalam merancang kegiatan pembelajaran atau proses belajar mengajar yang masih monoton. Rendahnya kemampuan guru dalam merancang media pembelajaran yang kreatif dan menarik bagi siswa.

Melihat kondisi dalam pengembangan media pembelajaran yang kreatif dan menarik bagi siswa. Pelaksana IbM melibatkan guru-guru di SMA Muhammadiyah 11 Padangsidimpuan. Kegiatan pelatihan dan pendampingan dalam pengembangan media pembelajaran dipandang perlu untuk meningkatkan kemampuan guru-guru.

\section{Permasalahan Mitra}

Berdasarkan hasil analisis terhadap beberapa hasil penelitian dan hasil diskusi Pimpinan Daerah Muhammadiyah melalui Majelis Dikdasmen Kota Padangsidimpuan melalui wawancara dan observasi diketahui beberapa permasalahan dan kendala sebagai berikut: (1) Sebahagian besar guru-guru masih mengalami kesulitan dalam mengembangkan perangkat dan media pembelajaran. (2) Ketersediaan sarana dan prasarana yang dimiliki sekolah masih sangat terbatas. (3) Rendahnya kesempatan para guru-guru mendapatkan kesempatan 
$\begin{array}{lrr}\text { mengikuti } & \text { pelatihan/ } & \text { workshop } \\ \text { pemanfaatan } & \text { software } & \text { media }\end{array}$ pembelajaran. (4) Jangkauan teknologi informasi yang masih rendah, sehingga sekolah dan guru, kurang mendapatkan kesempatan informasi atau perkembangan software media pembelajaran.

\section{Solusi Yang Ditawarkan}

Berdasarkan hasil analisis situasi dan permasalahan yang dihadapi oleh mitra, tim dosen akan memberikan suatu solusi untuk mengatasi kesulitan guru dalam mengembangkan media pembelajaran yaitu: (1) Melaksanakan pelatihan pemanfaatan Microsoft Power Point, (2) Melaksanakan pelatihan Sofware Camtasia, (3) Melaksanakan pelatihan Mengkombinasikan Program Microsoft Power Point dan Camtasia, dan (4) Pemanfaatan media dalam proses pembelajaran

\section{METODE PELAKSANAAN}

Berdasarkan permasalahan mitra, sebagaimana yang ada pada Bab sebelumnya, maka solusi yang ditawarkan adalah: (1) Pembentukan dan pendampingan kelompok guru di SMA Muhammadiyah 11 Padangsidimpuan untuk mengatasi kesulitan dalam pembuatan media pembelajaran. (2) Menambah pengetahuan guru tentang pemanfaatan software dan media pembelajaran. (3) Menambah pengetahuan guru tentang perkembangan media pembelajaran yang bersifat IT.

Desain Ipteks dalam kegiatan pengabdian adalah sebagai berikut:

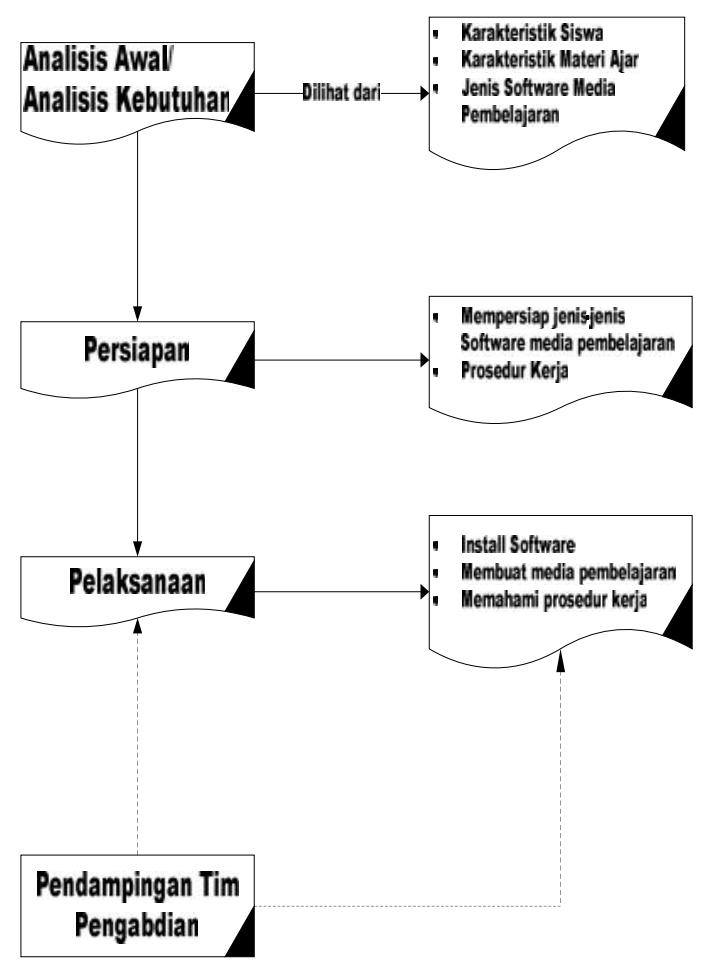

Gambar 1: Skema Pelaksanaan

Mekanisme Pelaksanaan Kegiatan: Pelaksanaan IbM ini mengikuti aktivitas pelaksanaan penelitian tindakan yaitu: Persiapan, Pelaksanaan, Observasi dan Evaluasi, serta Refleksi.

(1) Persiapan :

(a)Melakukan Koordinasi dengan LPPM Universitas Muhammadiyah Tapanuli Selatan dan SMA Muhammadiyah 11 Padangsidimpuan

(b)Sosialisasi dengan mitra yaitu SMA Muhammadiyah11Padangsidimpuan

(c)Penyusunan program IbM berdasarkan Analisis awal/ Analisis Kebutuhan

(2) Pelaksanaan

(a)Pembentukan dan pendampingan guru dalam mengatasi kesulitan dalam pengembangan media pembelajaran

(b)Pelatihan dalam pemanfaatan software pendukung dalam pengembangan media ajar

(c)Mendemonstrasikan penggunaan software media pembelajaran 
(d) Pendampingan dalam menyusun dan menyelesaikan media pembelajaran

(3)Observasi dan Evaluasi

Kegiatan observasi dilakukan secara langsung oleh tim Pelaksanaan IbM. Observasi berupa hasil kerja peserta (guru mitra) terhadap pemanfaatan software dan pemanfaatan media pembelajaran. Proses evaluasi dilaksanakan untuk mengetahui kekurangan dan kendala dalam pelaksanaan kegiatan IbM.

(4) Refleksi

Refleksi dilakukan bersama oleh tim Pelaksanaan IbM serta peserta (guru mitra). Hal ini dilakukan untuk mengetahui seluruh proses kegiatan IbM.

\section{HASIL DAN PEMBAHASAN}

Kegiatan pelatihan dan pendampingan dalam pengembangan media pembelajarandengan software pada kombinasi Microsoft Power Point dan Camtasia melibatkan guru-guru di SMA Muhammadiyah 11 Padangsidimpuan. Kegiatan pelatihan dan pendampingan dalam pengembangan media pembelajaran dianggap perlu bagi guru-guru agar dapat memperbaiki proses pembelajaran yang selama ini diterapkan oleh para guru.

Dalam pelaksanaaan kegiatan ini tim juga melakukan evaluasi kegiatan agar para guru yang masih belum memahami proses ini lebih baik. Media ini dilaksanakan oleh tim dengan mengajak mahasiswa sebagai narasumber yang terlebih dahulu mahasiswa dilatih untuk melaksanakan program Camtasia.

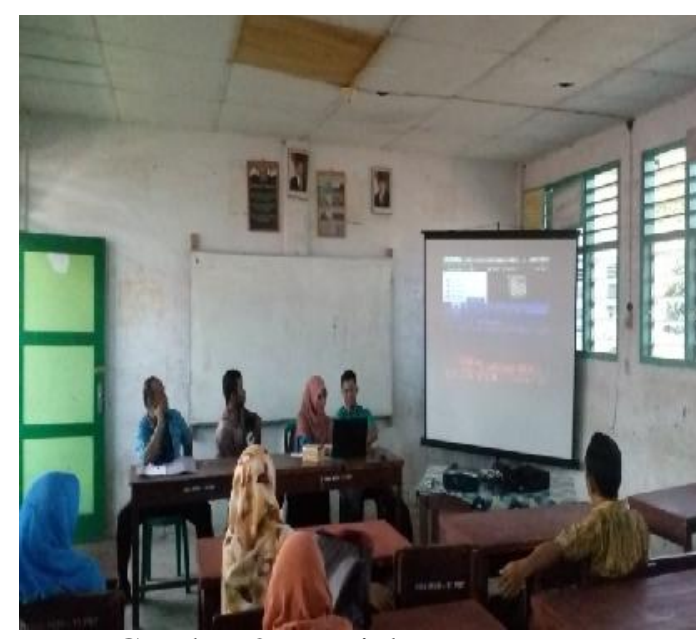

Gambar 2: Penjelasan tentang program camtasia

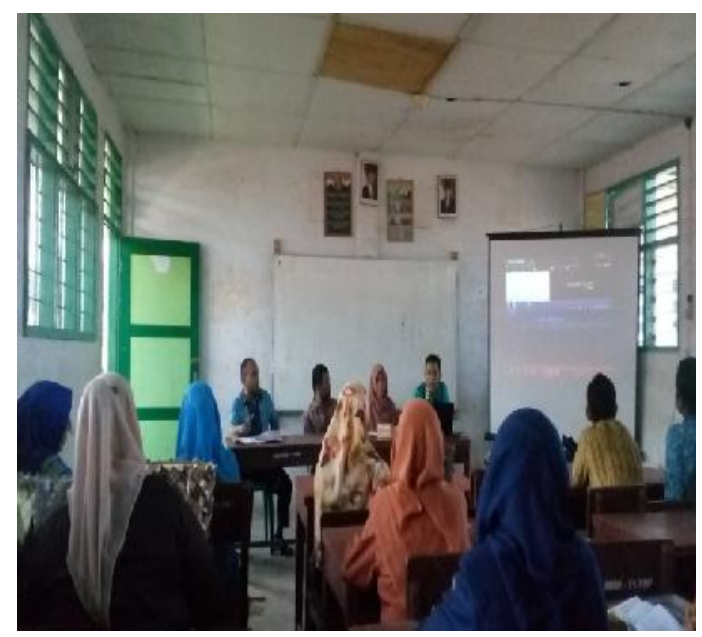

Gambar 3: Penjelasan tentang Mengkombinasikan Program Microsoft Power Point danCamtasia

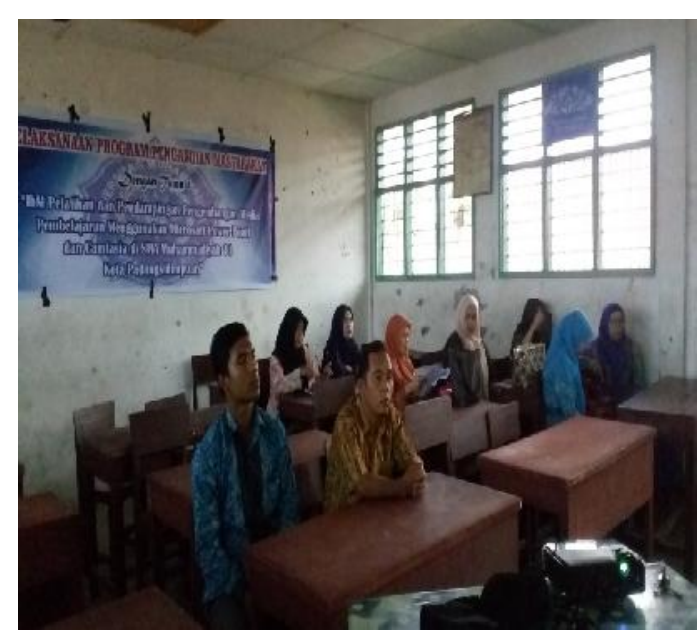

Gambar 3: Pelaksanaan pelatihan pembuatan media pembelajaran 
Dalam pelatihan dan pendampingan pengembangan media pembelajaran menggunakan Microsoft Power Point dan Camtasia di SMA Muhammadiyah 11 Padangsidimpuan. Pada program Iptek bagi Masyarakat ini para guru melakukan kegiatan dengan sangat antusias, serta meminta kepada tim pelaksana kegiatan untuk memaksimalkan kembali pelatihan pengembangan media pembelajaran yang ada untuk saat ini.

\section{SIMPULAN}

Berdasarkan hasil kegiatan pelatihan dan pendampingan pengembangan media pembelajaran yang telah dilaksanakan, maka diperoleh kesimpulan sebagai berikut: (1) Diperoleh feedback yang positif dari pihak sekolah, guru-guru di SMA Muhammadiyah 11 Padangsidimpuan selama kegiatan berlangsung. (2) Bertambahnya informasi terhadap media pembelajaran yang dapat membantu bahan pembelajaran bagi para guru. (3) Guru-guru mampu merancang media pembelajaran yang dapat disesuaikan dengan keadaan lingkungan sekitar (4) Tingginya motivasi dan permintaan untuk pengembangan bahan pelajaran melalui media pembelajaran yang lebih menarik.

\section{UCAPAN TERIMA KASIH}

Terima kasih kepada Universitas Muhammadiyah Tapanuli Selatan yang telah memberikan Dana Pengabdian Kepada Masyarakat tahun anggaran 2016.

\section{DAFTAR PUSTAKA}

Setiawan, Candra. (2011). pembuatan video materi ajar dengan camtasia pada pelatihan pengembangan materi ajar. Palembang: Pusbangdik Universitas Sriwijaya.

Team Lab Infokom. (2013). Microsoft Office Power Point 2013, Team Lab Infokom DPP Infokom@2013.

Utomo, Teguh Wahyu. (2009).Multimedia Learning; Prinsip-prinsip dan Aplikasi terjemahan dari Richard E. Mayer tahun 2001. Yogyakarta: Pustaka Press. 